\title{
Article
}

\section{Popularization of Science in Brazil: getting onto the public agenda, but how?}

\author{
Márcia Tait Lima, Ednalva Felix das Neves, Renato Dagnino
}

\begin{abstract}
The importance the Brazilian government has given in the last few years to the dissemination of science points out the necessity of a more discerning analysis about the establishment of this subject on the public agenda and the related public policies undertaken. This work tries to contribute to the debate as an inquiry about the policies to popularize and disseminate Science and Technology (S\&T) established by the Science and Technology Popularization and Dissemination Department, which was created in 2004. In order to do so, theoretical references from Public Policy Analysis, the Studies of Science, Technology and Society (SSTS), and Public Communication of Science are used. Furthermore, we analyze some of the results from research on Science and Technology Understanding carried out in Brazil in 2006. As a final point, this associated approach aims at identifying some of the limiting factors related to science dissemination actions in Brazil.
\end{abstract}

\section{Introduction}

The growing influence of Science and Technology (S\&T) on different dimensions of modern life makes the understanding of scientific technological questions more and more indispensable for the exercise of citizenship. A policy of science popularization, aimed at broadening the individual understanding of the world we live in, may stimulate public participation in choices and directives with regard to science and technology. Consequently, it may also contribute to the inclusion of the interests of social groups which traditionally have been excluded from the benefits the scientific and technological development can bring about. In this way, actions to promote the popularization of science can also be understood as strategies for stimulating social inclusion.

However, this theoretical perspective, despite having a reasonable logical sequence, is not so easily verifiable and applicable in the concrete practices of policies aimed at the popularization of S\&T. As this paper will illustrate, the popularization of science within an approach based on Studies of Science, Technology and Society (SSTS) and, in particular with a focus on social inclusion, involves components which go far beyond broadening public understanding of S\&T.

Our discussion of the relation between the popularization of S\&T and inclusion is centered on the actions of the Department of Dissemination and Popularization of Science and Technology (DEPDI) together with the Secretary of Science and Technology for Social Inclusion (Secis) of the Ministry of Science and Technology (MCT). We will analyze these actions through the theoretical references provided by Policy Analysis, SSTS and studies on Science Communication. We will also include some results with regard to the most recent national study, "Public perception of Science and Technology", carried out in Brazil (2006).

\section{The entrance of science popularization onto the Brazilian public agenda}

In order to understand the aspects related to the inclusion of the issue of science popularization into the Brazilian political agenda, we use the reference of Public Policy Analysis (PPA), given that it is useful to explain the role of the actors involved and the interests and values which shape the policies. Public Policy Analysis also incorporates a prospective orientation, being capable of providing elements for the improvement and reformulation of public policy [14]. 
According to Deubel, public policies (PPs) can be understood as action programs that represent the concrete realization of State decisions in the sense of inducing change in society. Public policies play a role in the construction of a new representation of problems that is capable of favoring the establishment of socio-political conditions for their resolution [14].

The inclusion of a issue into the political or public agenda occurs when the government gives this matter priority as a public problem and considers it able to be translated into a public policy. The problems making up the future agenda are chosen by individuals or groups who have enough power to influence governmental decisions with regard to the agenda's configuration [13]. With this consideration in mind, can we affirm that the topic has really entered the government's agenda and has become the focus of public policies? Should we have enough elements in order to answer this question affirmatively, others will be raised. In what way did the topic enter the political agenda? What are the views on the scientific popularization of S\&T that guide current policies formulated and implemented by DEPDI?

To start with, there are two concrete facts that make us believe science popularization is present in the public agenda of the current government. Firstly, the establishment of a formal structure within the government to deal with the matter - DEPDI - can be understood as a confirmation that the matter has become accepted as a problem incorporated in the agenda of the current government. Secondly, the inclusion of "Popularization of S\&T and Improvement in Science Teaching" in the "S\&T for Social Development" line of action of the 2007/2010 Ministry of Science and Technology Action Plan, which presents the directives of S\&T Innovation policy in Brazil. We base our affirmation on Deubel [3] when he relates the existence of a public policy to state-run institutions that take on, totally or partially, the responsibility of reaching determined objectives.

Most authors that use the PPA reference divide the public policy elaboration process into four basic stages which make up what they call policy cycle: i) Agenda Setting (entrance of the problem onto the political agenda); ii) Formulation; iii) Implementation (of decisions); iv) Evaluation. These stages should not be thought of in a static manner, for they make up part of a process (continuum); it is for this reason that they are also called public policy elaboration moments. Our objective is to contribute with a preliminary analysis of the first two stages of public policies directed at the communication and popularization of S\&T.

The identification/definition of a problem and its entrance onto the public agenda is the stage known as agenda setting. This process, according to Deubel [3], highlights that not all problems enter the public agenda. They are subjected to mechanisms of exclusion and inclusion. According to Deubel, a formal agenda and an informal (hidden) agenda exist and the problems that appear publicly on the agenda of an institution as the target of its actions are not always the tasks with which the institution really works.

Since its foundation in 2004, DEPDI has acted within the governmental structure and has been able to implement some concrete actions. The tasks formally taken on by this department include: formulating policies and implementing programs of S\&T popularization (promoting National S\&T Week, signing agreements with TV and radio stations in order to develop programs on science communication); collaborating with science teaching in schools, in partnership with the Ministry of Education (at a national level) and the Secretaries of Education (at a state level); supporting science centers and museums; supporting science communication events (including the training of science communicators).

Before 2004 governmental initiatives and programs which focused on the problem of lack of knowledge of S\&T among the Brazilian citizens were not configured as general public policies or nationally articulated programs. The actions were limited to the creation of financing possibilities through a small number of measures addressed to science centers and museums and a small number of incentives for science education through the Ministry of Education. Even after the creation of DEPDI, the public policies in this area continued to be widespread. In an article published in 2006, the then director of the Department, Ildeu de Castro Moreira, spoke of "proposals for the formulation of a science popularization policy" and "general directives for a public policy of science popularization". These words demonstrate the constructive nature in which policies related to the topic are still found.

In the same article, the author draws attention on the fact that public policies related to diffusion and popularization are included in the directives of the Ministry of Science and Technology's Secretary of Science and Technology for Social Inclusion (Secis), as indicated by the title of the article - "The Popularization of S\&T as an Element of Social Inclusion".

One of the aspects of social inclusion is to make it possible for every Brazilian to have the opportunity to acquire basic knowledge about science and its workings, thus giving this person 
the ability to understand his or her surroundings, broaden his or her opportunities in the job market and act politically with an understanding of cause. [10]

Moreira also signals that the insertion of DEPDI within Secis and the current administration's political prioritization of social inclusion cause the popularization of S\&T to become an "important line of action". Thus, the Department's allocation and its director's discourse show that public policies related to the popularization of S\&T have been conceived within a perspective of social inclusion. These choices are relevant, for they indicate a posture in terms of insertion of the matter on the public agenda and social construction of the problem.

\section{Public policies on science popularization: elements with regard to the social construction of the problem}

According to Sánchez, the understanding of the subjectivity of the definition of a problem that will be the focus of a public policy has materialized in the last two decades with the development of Public Policy Analysis within Political Science. Before this time, the problem was considered as an objective entity, and it was not even recognized as a stage in the political cycle. Upon admitting the lack of knowledge that the majority of the Brazilian population has with regard to S\&T as a problem that has penetrated the public agenda, we realize that this insertion could have taken place through other ministries. The link to the Ministry of Science and Technology indicates that the acknowledgement of this problem probably came from policy makers in the area of science and technology and members of the scientific community with a "sensitive view" of the question. The identification of these actors is important; for it is through their conceptions, how they perceive and what cause and effect relationships they establish that the representation of the problem will be constructed.

Deubel [3] points out that, before entering the political agenda, a situation should be recognized as a problem by an individual or social group which has ability and interest. This group will then work to define the problem and express it in adapted language in order to make it acquire a public dimension. Within this scenario, the media, academic and scientific circles, and political actors all have a key role in the definition and spreading.

Thus, some actors end up carrying out the task of mediation between society and the State for the creation of the public agenda. These actors are public mediators, comprising parties and their representatives; social mediators, comprising private representatives, such as intellectuals and scientists, that have legitimacy because of their strategic position or personal distinction; and administrative mediators, made up basically of civil servants or other professionals that hold positions within the State apparatus. These mediators are the main actors responsible for the definition of the problems that make up the public agenda.

Using the aforementioned theoretical reference to analyze S\&T popularization policies, Moreira, in the same article, notes the "challenge of social inclusion" in a society that "has accumulated an enormous set of social inequalities", creating difficulties for the "appropriation of scientific and technological knowledge" by the population. Moreira also makes several references to Brazil's educational problem, pointing to formal scientific education in Brazil as "dismal". Interviewed in August 2006, Moreira stated that "one of the greatest problems of the country is its education" and that "science popularization would be one of its alternatives to better the education" [11].

This link between the needs of social inclusion, an increase in the level of schooling and the popularization of science allows for the verification of the effects created by social inequality and low levels of education, as shown by the data of the 2006 S\&T Public Perception Poll, with regard to access to scientific technical knowledge and information. A good example of this is the fact that the poorest have a lower interest in S\&T.

In another passage of the interview, Moreira explains the relationship established between the popularization of S\&T, improvement in education and social inclusion. To him, a broader knowledge of S\&T, spurred by spreading and popularization policies, would help to promote a type of "school renovation", improving the quality of teaching. The virtuous cycle would be closed by better quality teaching which stimulates social inclusion.

The contextualization of the need to popularize S\&T in Brazil within a "global view" of social exclusion and poor quality education can, in principle, point to an adequate direction. In trying to 
establish a causal relationship among these "three issues" - exclusion, poor quality education and the lack of knowledge about S\&T - we noted that the lack of knowledge about S\&T is taken as a consequence of the condition of socio-economic and educational exclusion which a large part of the Brazilian population has to face. We could thus think of the question of popularization of science and technology as a problem that has its origin in two other permanent "larger problems" on the public agenda.

Other data corroborate this thesis. Thirty-seven percent of the people interviewed stated that they do not understand the matter (S\&T), which can lead to a lack of interest. Thirty-two percent declared that they do not look for information on the matter because they do not understand it.

But what other actions and relations could a S\&T popularization public policy establish with other policies to improve education and the eradication of social inequalities? It seems that in order to construct policies which allow for positive changes in this global setting, the adoption of a critical posture on the understanding of education and the diffusion and popularization of S\&T and it objectives would be necessary.

\section{Some concepts to deal with the problem of the public communication of science and the popularization of science}

In order to analyze science popularization policies, it is important to understand some conceptual models and relations that involve the problem of the so-called public communication of science, understood as a fundamental aspect of popularization. In order to do this, we will begin by referring to the idea of the three levels of ignorance involving the public communication of science as proposed by Leite [6] and attempting to relate them to the results of the S\&T Public Perception Poll [12]. For Leite, the problem of public communication of science involves three levels of ignorance:

1) Base ignorance, or the lack of fundamental concepts about S\&T that should make up the basic education of individuals. This point is intimately related to the problem of formal and non-formal education.

2) Ignorance about what is happening, or a lack of information about current matters of science that require constant accompaniment. In this case, we can mention data from the poll which show that $84 \%$ of the interviewees declared they were not aware of the research institutions existing in Brazil. Among the $16 \%$ who declared awareness, $47 \%$ of them mentioned public and mixed entities (such as the Oswaldo Cruz Foundation/FIOCRUZ) or Universities/Colleges (46\%), with the University of São Paulo (USP) and the University of Campinas (UNICAMP) being the most frequently cited. Eighty-six percent also declared they did not know any scientist. It is important to point out that these institutions are the ones which appear the most in the media, thus explaining their recognition by the population. This data not only points out the population's ignorance in relation to what is taking place in S\&T, but it also shows the difficulty of the inclusion of this population in the socalled scientific culture. The institutions doing science in Brazil - as well as their workers (the scientists) - are clearly far from the reality of the majority of the population.

3) Ignorance of the implications, which involves an inability to contextualize scientific matters in their political, legal, ethical and social dimensions. An interesting piece of data from the Public Perception Poll [12] that can be related to this dimension of the problem was that $32 \%$ ignored (or preferred not to answer about) what determines the direction of S\&T.

Still with regard to the data of the 2006 Public Perception Poll, it was revealed that $58 \%$ of the population is uninterested or has little interest in S\&T. This lack of interest in the topic from more than half of the interviewees becomes even more disturbing when understood as the first step that may or may not lead to a critical understanding of the relation between ST\&S and the possibility of public participation. The creation of conditions for social participation in the processes of decision-making with regard to S\&T depends on the existence of an educational system which favors the development of cognitive abilities and promotes a change of view with regard to the nature of the scientific technological phenomenon, as well as its products [7]. 


\subsection{Models of public communication of $S \& T$}

Within the terminology encompassing the public communication of science, the concepts of popularization and, to a greater extent, vulgarization have been generally used in association with the so-called scientific knowledge deficit model and the idea of scientific illiteracy. In this model, the average public, which lacks knowledge about S\&T, should receive this content in the simplest and most easily assimilated way possible. It relates to a view of science as a motor of progress, as a way of knowledge that is linear and independent from the social surroundings. The fact that $47 \%$ of the interviewees in the research on public perception (2006) see scientists as people who contribute to the scientific and technological development of the country and that $33 \%$ see them as contributing to solve the problems of the people, both help to maintain an idea of science as the engine of progress. Furthermore, it is important to say that the other $60 \%$ of the interviewed see scientists as "intelligent people who do useful things for humanity".

In this regard, the perspectives of the popularization of S\&T are linked to the broadening of public understanding and knowledge about the benefits brought about by the scientific technological activity. The deficit model, which was predominant in the first science popularization policies, privileges the scientist and positions science communication as having only one direction - from the specialist to the lay public. This is based on the superiority of scientific knowledge over tradition and on the public's limited ability to understand and interpret $S \& T$ issues.

This limited view of the public communication of S\&T was subject to criticism, especially coming from a group linked to STS Studies and more critical segments within science communication itself. The criticism related to the simple deficit model has ended up leading to changes in the science popularization models that have been adopted in public policies throughout the world. Other models have gained ground, such as the complex deficit model and the democratic model. In the complex model, popularization has the broader objective of promoting a greater understanding and valuing of scientific technological activities, in addition to broadening the capacity of public participation. However, a unidirectional view of communication and of science as the true and superior way of knowledge still prevails.

Finally, the democratic model has emerged as the most recent science popularization model. It seeks to spur the participation of diverse social actors in the decisions and resolutions of conflicts surrounding S\&T. This model starts from a view of scientific knowledge as partial, provisional and controversial. We can note the influence of criticisms and reflections promoted by STS Studies in this model. Its justification is mainly political - in other words, in a democracy everyone has the right to decide about issues that affect their life [8].

When we observe S\&T popularization policies in place in Brazil, we notice that the importance of these conceptual differences is not unknown. However, when incorporating them into political actions, there seems to be a gap that is difficult to bridge. The policies in the area of S\&T spreading and popularization still seem to be strongly influenced by the idea that the lack of public understanding about S\&T can be cured by exposing the public to more enchantments of science and technology and that this access should lead to social inclusion. Only few initiatives which come close to the ambitions of the democratic model are truly linked to a proposal of broadening public participation in science.

\section{The importance of the SSTS field insertion}

The Studies of Science, Technology and Society (SSTS), begun in the 1950s, consist of an interdisciplinary field with heterogeneous approaches. Their objective is to understand the relations between science, technology and society or to understand science and technology through their social context. The contributions from this field, namely from what is referred to as STS education, aggregate interesting methodological proposals in order to comprehend and understand the science-technologysociety relations within the context of formal and non-formal education. These methodologies propose a critical/reflective outlook on S\&T, which goes beyond the understanding of concepts and benefits associated with S\&T. The conventional form of education has been questioned by STS education because of its contents and organization, as well as because of the teaching methodologies used.

The Studies of Science, Technology and Society point to public participation in decisions about and the evaluation of the development of science and technology. In turn, public participation points to the need for education that is coherent with the presuppositions of those studies. Considering the relation between science, technology and society implies outlining an education consistent with this perspective. In other 
words, it means education which does not present S\&T as neutral. Rather S\&T is presented as conditioned by values and interests and, for this reason, open to questioning and permeated by choices [4].

STS education introduces related programs and subjects in the different areas of teaching, thus guiding students to rethink the image of S\&T within society. Scientific and technological knowledge was viewed until the mid- $20^{\text {th }}$ Century as a path to the redemption of humanity's evils. However, the awareness of not having a linear relation between S\&T and the social well-being was the stimulating factor in the emergence of these questions [7]. This perception was the basis firstly to question what paths science and technology are taking at national level so that the citizens may later participate in policy formulation and, secondly, to demand that the benefits from science and technology not be concentrated, but rather shared.

Precisely as those issues and the public agenda involve a social construction process which should consider the interests of all the actors, also the paths of scientific and technological development are socially negotiated. In that sense, the formulation of public policies for science popularization aligned with the expectations of the democratic model could be aided by reflexive and practical contributions from Science, Technology and Society Studies.

Despite suggesting the need for a partnership between Education and Popularization, the concrete actions of DEPDI are based on a model in which the dissemination of S\&T operates primarily as a support mechanism to improve the quality of science teaching. As we tried to show, the critics of the STS field and STS Education put the issue of knowledge democratization within a context of citizen participation and development of a critical and contextualized understanding of science. Thus, the scientific content should be democratized from new methodological approaches.

Specifically, among the public policy initiatives of science popularization in Brazil, the implementation of a National Week of S\&T, the Mathematics Olympics and the establishment of science centers and museums were those that received more support. Other attempts, such as expanding partnerships with TV and radio stations for the creation of programs of dissemination, also obtained some investments and results, but still unsatisfactorily.

As demonstrated by the detailed proposals contained in the fourth strategic priority of the Action Plan for 2007/2010 from the Ministry of Science and Technology, called "S\&T for Social Development", the support to this type of activities will be apparently maintained within future popularization policies. This is demonstrated by the estimated allocation of resources: $20 \%$ to the "Support of Dissemination Projects and Events and Science and Technology Education", 20\% to "Support to the Establishment and Development of S\&T Centers and Museums", 24\% to "Digital Multimedia Content for Science Education and Popularization of S\&T on the Internet," and the largest share, $36 \%$, to the "Olympics of Mathematics of the Brazilian Public Schools."

It is important to note that, out of the total proposed expenditure for the Action Plan implementation, only $2 \%$ is destined to the fourth priority, which is embedded in the line of action "Popularization of Science, Technology and Innovation and Improvement of Science Education". On the one hand, the low estimates of resources demonstrates that despite the emergence of the popularization theme and its inclusion on the public agenda, this issue is still far from a priority. Moreover, the allocation of resources to the scheme for popularization and education improvement appears as the continuation of a policy to support popularization activities based on a model implementing science promotion through events; creation of visitor attractions, and a technical upgrading in science teaching.

Inasmuch this work suggests the need for integrating the critical vision of Studies of Science, Technology and Society, highlighting the contribution from STS Education, we believe that public policies based on the actions above are not sufficient to promote public participation and inclusion, consistently with the democratic model of science popularization. These targets involve a concern with the integration of STS education at various levels of formal education and a training project, addressed not only to teachers and students but also to professionals who work extensively on popularization. These professionals, involved in the development and maintenance of projects such as science museums, would be rewarded with the critical and methodological contribution from the STS field, thus being able to promote a kind of popularization targeted on citizens and critics participation, much less focused on "learning or interacting" with scientific concepts. The popularization of methodologies based on what we refer to as "funny learning and enchantment with science" - traditionally used in science museums around the world - may be sufficient to act against the "ignorance of basics," but it is still inadequate to promote a proper understanding of the "ignorance of the context and its implications" [6], mainly in the scenario of economic inequity and educational deficits in countries such as Brazil. 


\section{Final considerations}

The issue of S\&T popularization has gained momentum on the public agenda in central as well as in peripheral countries. In the case of Brazil, this policy entered the agenda in a way explicitly linked to the problem of social inclusion. In this article we attempt at showing that in order to act along this path - to include and widen public participation -S\&T popularization actions should be thought of and implemented taking into account the contributions from Science, Technology and Society Studies and a critical view of public science communication. The objective of this union is to foster an understanding of S\&T in its economic, cultural and political dimensions. In this analysis, SSTS approaches constitute an essential reference for public policy formulation and implementation in the S\&T popularization area, thus keeping with a democratic model of public communication and with the objectives of social inclusion.

The improvement of the Brazilian policy of S\&T popularization therefore depends on joint and consistent actions from DEPDI and the Ministry of Education, with the objective of introducing STS education into the curriculum of the various levels of education. For this reason, the training of professionals to work with STS education in formal and informal settings appears to be an urgent measure.

Even though the current proposals and actions of DEPDI prove to be fundamentally related to offering support to formal education, they seem to seek a type of technical and methodological modernization of formal education (use of the Internet, videos, etc.) focused on creating places where to promote occasions of contact with S\&T as well as admiration of science in itself (Science Museums, National Week of S\&T, etc.). Following our analysis, these public policies would need to be complemented by more structured measures, such as those mentioned above, within the system of formal education and with professional training actions on popularization aligned with the perspective of Science, Technology and Society Studies and social inclusion.

Our analysis of the early stages - agenda setting and formulation - of the science popularization public policies under way in Brazil reveals a deficiency in the outlining of the issue of popularization and, consequently, in the actions adopted. As discussed, this deficiency derives from, among other factors, a non-appropriation of the contributions of Science, Technology and Society Studies, especially STS education, in order to think about the relation between science, technology and social inclusion.

Translated by Robert Gartner

\section{Notes and references}

[1] R.P. Dagnino, Enfoques sobre a relação Ciência, Tecnologia e Sociedade: neutralidade e determinismo, in DataGramaZero - Revista de Ciência da Informação 3(6), 2002. Available at http://www.dgz.org.br/dez02/Art_02. Accessed on 08/11/2007.

[2] R.P. Dagnino and H. Thomas, Introdução, in: R.P. Dagnino and H. Thomas (org.), Panorama dos estudos sobre ciência, tecnologia e sociedade na América Latina, Taubaté, Cabral (2002).

[3] A.R. Deubel, Políticas Públicas: Formulación, Implementación e Evaluación, Bogota, Ediciones Aurora (2006).

[4] L. Fraga, O curso de graduação da Faculdade de Engenharia de Alimentos da Unicamp: Uma análise a partir da Educação em Ciência, Tecnologia e Sociedade, Master's Thesis defended at DPCT/IG/UNICAMP. Campinas/SP (2007).

[5] Instituto Brasileiro de Geografia e Estatística (IBGE), in http://www.ibge.gov.br.

[6] M. Leite, Contribuição do Jornalismo Científico ao desenvolvimento científico brasileiro, communication presented at roundtable entitled "A população informada: divulgação científica", included in the National Conference of Science, Technology and Innovation, in Brasilia, on 20/09/2001.

[7] I.V. Linsingen, CTS na educação tecnológica: tensões e desafios (2006). Available at www.ige.unicamp.br/gapi/Irlan\%20CTS.pdf. Accessed on 20/10/2007.

[8] M. Lozano, Programas y experiencias en popularización de la ciencia y la tecnología. Panorámica desde los paises del Convenio Andres Bello, Bogota, Convenio Andres Bello (2005).

[9] MCT/Departamento de Difusão e Popularização da C\&T/SECIS, in http://www.mct.gov.br/index.php/content/view/50875.html. 
[10] I. de Castro Moreira, A inclusão social e a popularização da ciência e tecnologia no Brasil, Revista Inclusão Social - IBICT, vol. 1 n 2 (2006).

[11] I. de Castro Moreira, Entrevista para Boletim UFMG, n. 1541- year 32, 28/07/2006 (2006).

[12] S\&T Public Perception Poll In Brazil (Pesquisa Percepção Pública C\&T No Brasil) (2007). Available at http://www.mct.gov.br/index.php/content/view/50877.html. Accessed on 13/10/2007.

[13] P.M. Sánchez (org.), Análisis de Políticas Públicas, Granada, Ed. Universidad de Granada (2006).

[14] A.V. Velásquez, El estado y las políticas públicas, Bogota, Almudena Editores (1999).

[15] C. Vogt (org.), Cultura Cientifica: Desafios, São Paulo, Edusp/Fapesp (2006).

\section{Authors}

Márcia Tait Lima. Márcia holds an undergraduate degree in Social Communication from the State University of São Paulo (UNESP). She currently is a master's degree student in Scientific and Technological Policy at the State University of Campinas (UNICAMP). She is a researcher in the Analysis Group of Innovation Policy (Gapi) at UNICAMP and at the Open Laboratory of Interactivity for Science Communication (Labi) of the Federal University of São Carlos (UFSCar), and an associate researcher at the Laboratory of Advanced Studies in Journalism (Labjor) at UNICAMP. She holds a scholarship from the State of São Paulo Research Foundation (FAPESP).

E-mail: marcia_tait@yahoo.com.br.

Ednalva Felix das Neves. Ednalva holds an undergraduate degree in Economic Sciences from the Methodist University of Piracicaba (UNIMEP). She currently is a master's degree student in Scientific and Technological Policy at the State University of Campinas (UNICAMP). She is a researcher in the Analysis Group of Innovation Policy (Gapi) at UNICAMP. She holds a scholarship from the State of São Paulo Research Foundation (FAPESP). E-mail: dinefex@yahoo.com.br.

Renato Peixoto Dagnino. Renato holds a post-doctorate in Science Policy Research Unit from the University of Sussex. He is a tenured professor at the Department of Scientific and Technological Policy of the State University of São Paulo (UNICAMP) and coordinator of the Analysis Group of Innovation Policy (Gapi) at UNICAMP. E-mail: rdagnino@ige.unicamp.br.

How to CITE: $\quad$ M. Tait Lima, E. Felix das Neves and R. Dagnino, Popularization of Science in Brazil: getting onto the public agenda, but how?, Jcom 07(04) (2008) A02. 